\title{
Molecular parameters linking thyroglobulin iodination with autoimmune thyroiditis
}

\author{
George Carayanniotis
}

Divisions of Endocrinology and Biomedical Sciences, Faculty of Medicine, Memorial University of Newfoundland, St. John's, NL, Canada

\begin{abstract}
Increased iodide intake has been linked to the development of hypothyroidism and/or autoimmune thyroiditis in humans and animals, but the mechanisms involved remain poorly understood. Increased ingestion of iodide is likely to have pleiotropic effects on either metabolic or immunological processes. Within the latter domain, recent interest has been focused on two areas: a) the role of iodinated peptides in thyroglobulin ( $\mathrm{Tg}$ ) - the molecular site of biosynthesis and storage of iodotyrosines and iodothyronines - in triggering an autoimmune cascade, and $b$ ) the role of iodine-induced apoptosis/necrosis of thyrocytes in the disease process. This review presents a brief summary of recent findings in these research areas.
\end{abstract}

Key words: Autoimmunity, Iodine, NOD.H-2h4 mice, Thyroglobulin, Thyroid autoimmunity, Thyroiditis

\section{A. INTRODUCTION}

Epidemiological studies have linked increased iodide intake from dietary or other sources to the development of hypothyroidism, and it appears that in several-though not all-cases, this phenomenon has an autoimmune basis. ${ }^{1}$ How does iodine trigger pathogenesis? Although work with animals prone to developing autoimmune thyroiditis after high iodide intake, such as Cornell strain (CS) chickens, ${ }^{2}$ diabetesprone BioBreeding/Worcester (BB/W) and Buffalo rats, ${ }^{3,4}$ and non obese diabetic (NOD).H-2h4 mice, ${ }^{5,6}$

\footnotetext{
Address for correspondence:

George Carayanniotis, Faculty of Medicine, Memorial University of Newfoundland, 300 Prince Philip Dr. St. John's NL, Canada A1B 3V6, Tel.: 1-709-777-6967,

Fax: 1-709-777-7010, e-mail: gcarayan@mun.ca

Received 16-03-10, Revised 05-09-10, Accepted 04-11-10
}

has provided valuable insights, an understanding of the events that initiate the autoimmune cascade is still lacking. The emerging picture indicates that the genetic background of the host plays a critical role at different levels, thus making it unlikely that a single mechanism of iodine-induced pathogenesis is responsible for experimental or human thyroiditis. The recommended daily allowance of iodine by the World Health Organization is $150 \mu \mathrm{g}$ for adults, ${ }^{7}$ i.e. approximately $3 \mathrm{x}$ the amount $(52 \mu \mathrm{g})$ of iodine the gland must take up daily to remain in balance. ${ }^{8}$ However, the average dietary iodide intake can often exceed this level, ranging from $5 \mathrm{mg}$ per day in populations consuming seaweed ${ }^{8,9}$ to $500 \mu \mathrm{g}$ in the United States and Canada. ${ }^{710}$ Most persons tolerate chronic excess of iodide intakes of up to $600 \mu \mathrm{g}$ per day in the European Union, while $1100 \mu \mathrm{g}$ per day in 
the United States is declared as tolerable for adults. ${ }^{8,11}$ This has sparked debate as to whether iodide intakes of 300-400 $\mu \mathrm{g}$ per day should be considered excessive or adequate. ${ }^{12,13}$ To compound the issue, the amount of iodine in individual foods and water can vary by a factor of $100,{ }^{14,15}$ rendering quantitation of iodide intake extremely difficult. Thus, values of the median urinary excretion rate above $300 \mu \mathrm{g} / / 1$ have been considered as indices of excessive iodide intake associated with increased risk of hypothyroidism. ${ }^{13}$ Despite several studies (reviewed in 8,10), it remains unknown if and how iodide intake, at dietary levels close to the tolerable limits, influences development of autoimmune thyroiditis in euthyroid individuals over long time periods, and animal models of autoimmune thyroiditis have not yet addressed this issue. It appears likely, however, that due to genetic factors, general recommendations may not be equally applicable to various populations and different countries of the world. ${ }^{13}$

Within an immunological context, iodine may mediate thyroiditis induction via at least two mechanisms: a) by increased post-translational modification of thyroglobulin $(\mathrm{Tg})$, an event which may enhance the immunopathogenicity of this molecule as detailed further in this review; and b) via apoptotic/necrotic effects of thyrocytes, a step that could initiate presentation of thyroid antigens at immunostimulatory levels. This review summarizes recent findings related to these issues with emphasis on Tg immunogenicity, as this has been more extensively studied.

\section{B. EFFECTS OF IODINE ON THE IMMUNOGENICITY OF Tg}

\section{B.1. Tg: a prohormone with strong pathogenic potential}

Induction of experimental autoimmune thyroiditis (EAT) by challenging animals with Tg is well known since 1956 from the pioneering studies of Rose and Witebsky in rabbits. ${ }^{16}$ In recent years, the view that the intrinsic pathogenicity of $\mathrm{Tg}$ merits detailed study at the molecular level has been strengthened mainly by two lines of research. First, linkage and association studies have highlighted $\mathrm{Tg}$ as the first thyroid-specific susceptibility gene in human autoimmune thyroid disease. ${ }^{17-19}$ This has shed new light on the molecule for which general clinical interest was previously limited to its diagnostic value as a target of autoantibodies. Second, a series of EAT studies by several laboratories have delineated small [(9-40 aa (aminoacids) length] peptides with pathogenic potential within the 2749 aa sequence of $\mathrm{Tg} .{ }^{20,21}$ These peptides encompass mostly cryptic T-cell determinants, i.e. epitopes to which Tg-primed T cells do not respond in vitro and, conversely, peptide-primed $\mathrm{T}$ cells which are not activated by Tg in vitro. This "cryptic self" is not of minor importance since host genetics and environmental factors such as diet may promote both peptide generation over threshold levels and immunostimulatory conditions that can trigger autoreactive $T$ cells. The mode by which iodine influences the formation of such epitopes is, therefore, an important step toward the understanding of pathogenesis.

\section{B.2. Influences of iodine on the generation of pathogenic Tg T-cell determinants}

Based on iodine involvement, pathogenic Tg peptides have been divided into three categories: a) peptides that contain hormonogenic sites, b) peptides that contain iodotyrosyl residues, and c) non-iodinated peptides.

\section{B.2.1. Pathogenic Tg peptides containing hormonogenic sites}

The 12mer Tg peptide (aa 2459-2560) containing thyroxine (T4) at aa position 2553, [T4(2553)], was the first T-cell determinant reported to induce $\mathrm{EAT}^{22,23}$ and subsequently it was found to elicit granulomatous EAT $^{24}$ and proliferative as well as cytotoxic $\mathrm{T}$ cell responses. ${ }^{23,25}$ Later, it was shown that the $12 \mathrm{mer}$ peptide (1-12) containing T4 at position 5, [T4(5)],the most active hormonogenic site of $\mathrm{Tg}$, even at low iodine availability, ${ }^{26,27}$ induced weak EAT as well as $\mathrm{T}$ cell responses. ${ }^{28}$ By contrast, the $12 \mathrm{mer}$ peptides containing T4 at positions 2567 and 2746 were devoid of immunopathogenicity. ${ }^{28}$ Additional work with $H L A$ $D R B 1^{*} 0301$ (DR3)-transgenic mice which carried no murine MHC class II antigens demonstrated that only $\mathrm{T} 4$ (5) was mildly stimulatory for Tg-primed $\mathrm{T}$ cells, indicating that the T4-containing peptides are not dominant epitopes presented by DR3 molecules. ${ }^{29}$ This was confirmed recently after sequencing DR3-bound peptides isolated from the thyroid tissue of a patient with Graves' disease. ${ }^{30,31}$ In CBA mice, the T4(2553) 
determinant was classified as a subdominant epitope as it activated in vitro $\mathrm{T}$ cells, previously primed with either human or mouse $\mathrm{Tg}$, for thyroiditis transfer. ${ }^{28,32}$ An analogue containing thyronine (T0) at position 2553, [T0(2553)], was also found to be immunogenic in CBA mice and it activated peptide-primed T cells for thyroiditis transfer ${ }^{28}$ suggesting that the presence of four iodine atoms within the T4 structure was not the only coefficient of immunogenicity. From a physiological standpoint, this is of limited importance as iodothyronine formation in vivo only occurs by the coupling of iodotyrosyl residues. Non-iodinated tyrosyl residues may be cross-linked to yield dityrosyl residues, which are unrelated to iodothyronines. ${ }^{33}$ Interestingly, it was found that LNC from mice challenged with the T4(2553) peptide could not be crossstimulated in vitro with the T0(2553) analogue and this regimen failed to generate effector cells that could transfer EAT. These results suggested that the iodine atoms sufficiently modify the peptide-MHC complex to elicit distinct $\mathrm{T}$ cell clones that recognize only the iodinated determinant. This concept was subsequently confirmed with pathogenic Tg peptides containing iodotyrosyl residues (see below). Three main conclusions were drawn from this collective work: a) the presence of the two-phenyl-ring side chain of T4 within a Tg peptide is not sufficient to impart immunogenicity to that fragment; $b$ ) while the removal of the four iodine atoms from the T4(2553) peptide does not abrogate its immunogenicity, their presence might activate additional pathogenic clones that recognize only the iodine-modified peptide; and c) T4-containing peptides are not major Tg epitopes presented by DR3 molecules.

\section{B.2.2. Pathogenic Tg peptides containing iodotyrosyl residues}

We have previously reported that three tyrosinecontaining peptides, p117 (aa 117-132), p304 (aa 304318), and p1931 (aa 1931-1945), have been found to activate autoreactive T cells and cause EAT in CBA/J mice only in their iodinated (i.e. iodotyrosyl-containing) form, whereas the non-iodinated analogues are not immunogenic. ${ }^{34}$ Peptide modification by the bulky iodine atom (atomic radius $\sim 133 \mathrm{pm}$ ) seemed to facilitate either peptide binding to MHC or recognition of the neoantigenic determinant by distinct clones in the available T-cell receptor repertoire. Further work, however, showed that iodotyrosyl formation within other Tg peptides had variable effects on immune recognition as it enhanced (p179, aa 179-194), suppressed (p2540, aa 2540-2554) or did not alter (p2529, aa 2529-2545) their established immunogenicity. ${ }^{35}$ Interestingly, such effects seemed not to influence the weak pathogenicity of these peptides. To investigate how a single iodine atom could affect recognition at the clonal T cell level, a panel of T-cell hybridoma clones were generated against the 16 mer peptide p179 or its iodinated analogue I-p179. It was found that iodination of Y192 had unpredictable effects: some clones were activated only when the iodine atom was present, others when the iodine atom was lacking, and yet other clones were activated by both the p179 and I-p179 analogues, tolerating the presence of iodine. ${ }^{36}$ This concept has also found support for B-cell epitopes via the use of monoclonal antibodies (mAbs). ${ }^{37,38}$ The implications of the above findings were two-fold. First, the results suggested that the identified iodinated peptides must be expressed intrathyroidally under steady-state conditions since adoptively transferred peptide-specific T cells mediated EAT. Second, it appears that formation of iodotyrosyl residues within a neoantigenic Tg determinant may have variable and unpredictable effects on $\mathrm{Tg}$ immunogenicity and pathogenicity as this event can turn either on or off the activation of individual effector T cell clones, depending on the particular site. The relative position of pathogenic Tg peptides containing iodine is shown schematically in Figure 1.

\section{B.2.3. Pathogenic Tg peptides lacking iodine}

The delineation of several (at least 15) non-iodinated $\mathrm{Tg}$ peptides with pathogenic potential has been previously reviewed. ${ }^{20,21}$ The role, if any, of iodine in promoting the generation of these peptides can only be suggested indirectly from studies showing that the structure, ${ }^{39}$ as well as the proteolytic degradation, ${ }^{40,41}$ of Tg is affected by its iodine content. This view is supported by our findings ${ }^{42}$ demonstrating that processing of highly iodinated $\mathrm{Tg}$ in macrophages or dendritic cells leads to selective activation of a T-cell clone specific for the non-iodinated peptide (2495-2510). This response was not observed when $\mathrm{Tg}$ with a physiological iodine content was processed by the same antigen presenting cells (APC) and it was selective as it did not lead to activation of a T-cell clone directed 


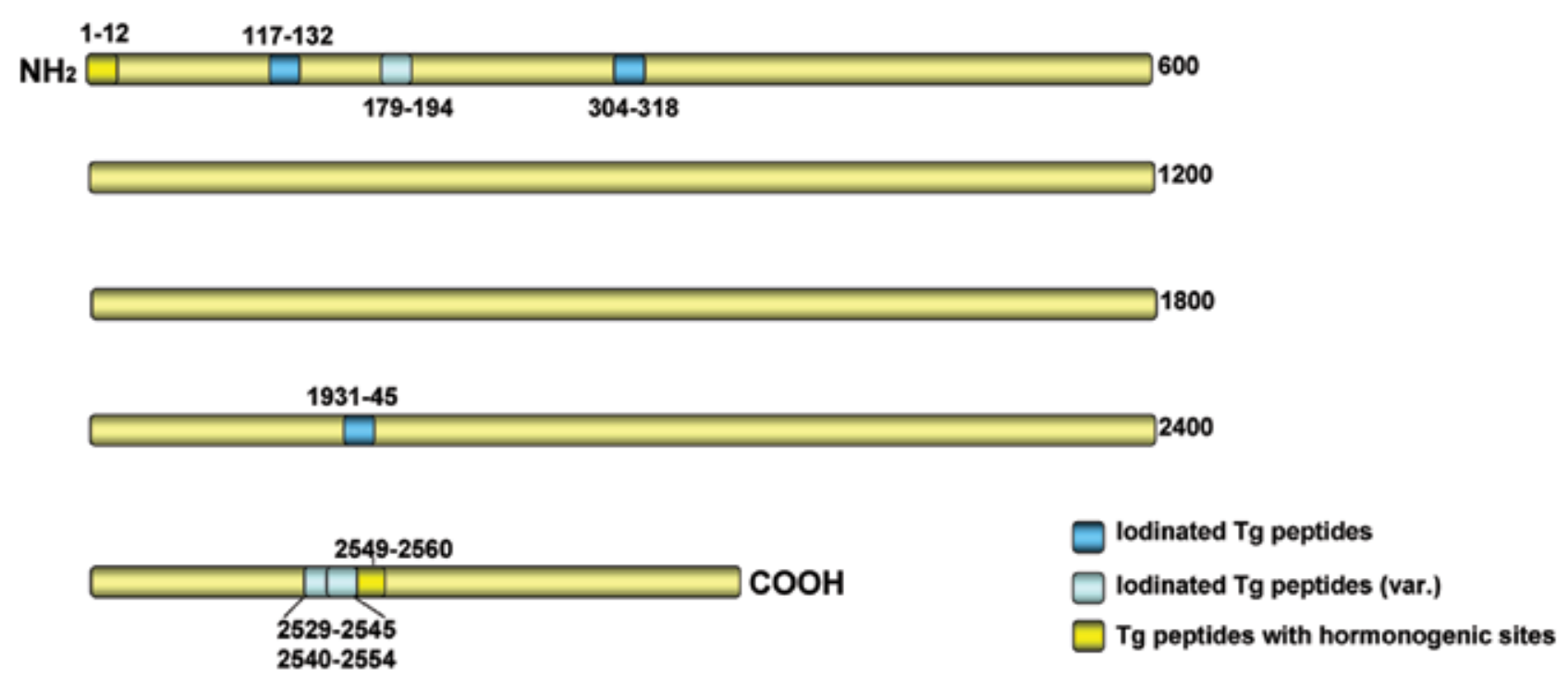

Figure 1. Schematic diagram (not to scale) indicating the relative positions of pathogenic thyroglobulin (Tg) peptides containing iodine. Dark blue: peptides that are pathogenic only in their iodinated (iodotyrosyl-containing) form; light blue: peptides in which the addition of iodine exerts variable effects on existing pathogenicity; gold: peptides containing hormonogenic sites. Numbers denote amino acid coordinates without taking into account the leader sequence.

against a different non-iodinated pathogenic peptide. In another study, a hormonogenic carboxy-terminal fragment of $\mathrm{Tg}$ was released during enzymatic or metal-catalyzed oxidation of Tg in vitro. ${ }^{43}$ Although these studies entailed supra-physiological levels of $\mathrm{Tg}$ iodination in vitro, they do suggest a mechanism whereby immune processing of $\mathrm{Tg}$ with increased iodine content might facilitate the "spreading" 44 of the immune response to non-iodinated but pathogenic $\mathrm{Tg}$ determinants. Other authors reported that the limited proteolysis in vitro of bovine and human $\mathrm{Tg}$, physiologically iodinated in vivo, was not affected by the iodine content of the $\mathrm{Tg}$ preparation. ${ }^{45}$

\section{B3. Regulation of $\mathrm{Tg}$-specific $\mathrm{T}$ cell reactivity by antibodies (Abs) recognizing iodinated determinants}

Abs binding to thyroid hormone are frequently found in patients with autoimmune thyroid disorders or animals developing EAT. ${ }^{46,47}$ We have previously shown that the $55 \mathrm{H} 8 \mathrm{mAb}$, representing this subset, recognizes the 5 iodine atom of the outer phenolic ring of T4 within the T4(2553) peptide, even after the peptide is bound to the major histocompatibility complex (MHC) $\left(\mathrm{A}^{\mathrm{k}}\right)$ groove. ${ }^{48}$ Thus, $55 \mathrm{H} 8$ inhibits activation of T4(2553)-specific T cells and significantly reduces their capacity to transfer EAT to naive mice. This suggested that circulating T4-specific Abs may cause suppression of T-cell autoreactivity directed to hormonogenic sites, in addition to any possible effects they may have on hypothyroidism due to T4 neutralization.

In vitro experiments have also shown that when APC process $\mathrm{Tg}$ bound to certain $\mathrm{Tg}$-specific $\mathrm{mAbs}$ such as $5 \mathrm{D} 2$ and $3 \mathrm{C} 4$, this leads to activation of T4(2553)-specific T cells. ${ }^{49}$ This effect was selective because it did not promote generation of other $\mathrm{Tg}$ peptides nor was it observed with other $\mathrm{Tg}$-specific mAbs. It required the Fc receptor-mediated uptake of $\mathrm{Tg}$ as well as an intracellular processing step because it was abolished after APC treatment with chloroquine or glutaraldehyde. Although not formally shown, such a process may be facilitated in principle by Abs directed to iodotyrosyl-containing peptides such as the I-p117 localized on the surface of the Tg molecule. ${ }^{34}$ These data suggested a mechanism whereby circulating anti-Tg Abs, frequently detectable even in euthyroid subjects, can precipitate $\mathrm{T}$ cell reactivity to iodinated pathogenic $\mathrm{Tg}$ determinants or help in the intramolecular "spreading" of the T cell response to cryptic Tg determinants during the later stages of disease.

\section{B4. Is iodide-rich Tg (I-Tg) a critical link in autoimmune thyroiditis?}

The unique capacity of $\mathrm{Tg}$ to store available io- 
dine forces the immune system to cope with a self antigen that is continually and variably modified by an environmental element supplied in our diet. $\mathrm{Nu}-$ merous earlier EAT studies have attributed a critical role to Tg iodination in the disease process. In some studies, hypoiodinated $\mathrm{Tg}$ did not activate $\mathrm{T}$ cells, whereas by raising the $\mathrm{Tg}$ iodine content to normal levels in vitro, the pathogenicity and/or antigenicity of the molecule was re-established. ${ }^{50-52}$ Toward the other end of the iodination spectrum, I-Tg was frequently ${ }^{42,53,54}$ but not always, ${ }^{55}$ shown to possess increased immunopathogenic potential. The studies with defined Tg epitopes, described above, have provided a mechanistic framework to understand those earlier findings: iodine-mediated enhancement of Tg may be explained on a structural basis via formation of iodothyronines or iodotyrosyl residues within neoantigenic determinants or may occur indirectly via effects on $\mathrm{Tg}$ processing that generates non-iodinated pathogenic T cell epitopes. At the same time, new unanswered questions have emerged, one of them being why is non-iodinated $\mathrm{Tg}$ not pathogenic ${ }^{51}$ given the large number of non-iodinated pathogenic peptides it contains. This appears even more paradoxical in view of the fact that iodine-free $\mathrm{Tg}$ was reported to be comparable to normal $\mathrm{Tg}$ in eliciting autoantibodies, implying $\mathrm{T}$ helper cell activation. ${ }^{51}$

Other findings have also shed doubt upon the concept that I-Tg constitutes a critical link in the pathogenetic process of autoimmune thyroiditis. For example, I-Tg may cause EAT with increased incidence and severity in SJL mice, ${ }^{42}$ but when these mice were fed a high iodide diet by drinking water with $0.05 \% \mathrm{NaI}$ for 10 weeks, their Tg did not show high iodine content ex vivo and the mice developed goitrous hypothyroidism with only focal mononuclear cell infiltrates and no autoreactive responses to $\mathrm{Tg} .{ }^{56}$ These symptoms were reversed upon $\mathrm{NaI}$ withdrawal. The influence of polymorphic genes was suspected by the fact that the symptoms were not observed in $\mathrm{CBA} / \mathrm{J}$ mice placed on a similar diet. Interestingly, a significant reduction of sodium/iodide symporter (NIS) mRNA was observed in CBA/J but not in SJL thyrocytes following $\mathrm{NaI}$ administration, allowing continuous iodide transport into the cells and possible failure to escape from the acute Wolff-Chaikoff effect. ${ }^{56}$ We have suggested that the iodide-induced goitrous hypothyroidism of SJL mice constitutes a model of the non-autoimmune hypothyroidism observed among subjects in several parts of the world where large quantities of iodide are consumed. ${ }^{1}$

Recent studies have made use of NOD.H-2h4 mice, a model of spontaneous autoimmune thyroiditis (SAT). Addition of $\mathrm{NaI}$ to the drinking water in these animals accelerates the onset of SAT from 7-10 months in the control mice to 2 months and significantly increases both its incidence and severity. ${ }^{5,6}$ However, the genetic background of this strain does not promote generation of I-Tg in vivo, and there is no evidence for differential B-cell or T-cell responses to Tg vs I-Tg in iodide-fed NOD.H-2h4 mice developing accelerated SAT. ${ }^{57}$ Indeed, in vivo formation of I-Tg in normal (i.e. non-goitrous) mice exposed to a chronic iodide-rich diet has not yet been reported. These findings contrast with the view of Barin et al. that iodine accelerates thyroiditis in NOD.H-2h4 mice by directly enhancing the antigenicity of Tg. ${ }^{50}$ Also, our data are not in agreement with earlier observations in obese strain (OS) chickens in which I-Tg formation is clearly observed during iodide-accelerated SAT. ${ }^{54}$ The reasons behind this discrepancy remain unknown. Equally controversial remains the role of Tg iodination in the pathogenesis of human thyroiditis: iodine has been suggested as playing an essential role in the recognition of human Tg by T cells, ${ }^{58}$ but other studies have reported that human $\mathrm{T}$ cells respond equally well to Tg preparations of varied iodine content. ${ }^{59}$ In any event, the cumulative experimental evidence does seem to suggest that enhanced iodination of Tg is not a sine qua non in iodine-induced thyroiditis and other genetic or epigenetic factors may be at play.

\section{INJURY OR APOPTOSIS OF THYROCYTES BY IODINE}

High doses of iodide have been known to cause direct thyroid cell injury in several animal species ${ }^{60-65}$ or human thyroid follicles in vitro. ${ }^{66}$ The resulting inflammatory trigger may initiate an autoreactive cascade in animals ${ }^{60,67}$ or humans with pre-existing goiters. ${ }^{68-71}$ However, events that occur when iodide is administered to iodopenic hosts may not necessarily reflect intrathyroidal changes occurring in euthyroid individuals on an iodide-rich diet (>500 $\mu \mathrm{g} \mathrm{I} /$ day). In 
this regard, work by Burek's laboratory has shown that the constitutive expression of the intracellular adhesion molecule-1 (ICAM-1) on thyrocytes of NOD.H$2 \mathrm{~h} 4$ mice is upregulated by iodine supplementation of drinking water, ${ }^{72,73}$ with concomitant increase in E-selectin and VCAM-1 expression on intrathyroidal endothelial cells. ${ }^{72}$ These events may promote the homing of autoreactive lymphocytes in the thyroid gland. The same group has presented evidence suggesting that NOD.H-2h4 thyrocytes, but not thyrocytes from other mouse strains not prone to thyroiditis, are characterized by a high constitutive expression of NADPH oxidase. This characteristic facilitates a spike in the generation of reactive oxygen species (ROS) upon iodine uptake, leading to upregulation of ICAM-1 expression. ${ }^{74,75}$ The implications are that anti-oxidants may have therapeutic value in preventing autoimmune thyroiditis, this being in agreement with earlier findings of Bagchi et al, who showed that antioxidants delay the onset of thyroiditis in OS chickens. ${ }^{76}$ Selenium has also been shown to prevent oxidative damage. ${ }^{77}$ The iodide-induced generation of extracellular $\mathrm{H}_{2} \mathrm{O}_{2}$ by thyrocytes ${ }^{75}$ may accelerate tissue damage via apoptotic/necrotic effects and the release of degraded thyroglobulin. ${ }^{78}$ Ultrastructural changes in thyrocytes of NOD.H-2h4 mice on an iodide-rich diet have been reported to occur in a dosedependent manner and include an increased number of lysosomes, swollen mitochondria, condensation of nuclear chromatin, and destruction of the epithelial cell membrane. ${ }^{79}$

\section{CONCLUSIONS}

High dietary iodide intake may lead to the development of thyroid autoimmunity via at least two pathways. First, iodide may epigenetically modify the $\mathrm{Tg}$ molecule and create iodinated neoantigenic determinants to which immune tolerance has not been established or alter the processing of $\mathrm{Tg}$ to facilitate generation of pathogenic but cryptic $\mathrm{Tg}$ determinants that may not contain iodine. Second, iodine may precipitate apoptotic/necrotic effects on thyrocytes, thus releasing increased amounts of thyroid antigens that can activate autoreactive T cells in situ or in thyroid-draining lymph nodes. The genetic background of the host may be permissive to one or both of these pathways that may act in synergy or independently of each other. The use of NOD.H-2h4 mice chronically exposed to iodide levels as a model of our dietary habits may allow the study of early pathogenetic events of thyroid autoimmunity.

\section{REFERENCE}

1. Markou K, Georgopoulos N, Kyriazopoulou V, Vagenakis AG, 2001 Iodine-Induced hypothyroidism. Thyroid 11: 501-510.

2. Bagchi N, Brown TR, Urdanivia E, Sundick RS, 1985 Induction of autoimmune thyroiditis in chickens by dietary iodine. Science 230: 325-327.

3. Allen EM, Appel MC, Braverman LE, 1986 The effect of iodide ingestion on the development of spontaneous lymphocytic thyroiditis in the diabetes-prone $\mathrm{BB} / \mathrm{W}$ rat. Endocrinology 118: 1977-1981.

4. Cohen SB, Weetman AP, 1988 The effect of iodide depletion and supplementation in the Buffalo strain rat. J Endocrinol Invest 11: 625-627.

5. Braley-Mullen H, Sharp GC, Medling B, Tang H, 1999 Spontaneous autoimmune thyroiditis in NOD.H-2h4 mice. J Autoimmun 12: 157-165.

6. Rasooly L, Burek CL, Rose NR, 1996 Iodine-induced autoimmune thyroiditis in NOD-H-2h4 mice. Clin Immunol Immunopathol 81: 287-292.

7. Iodine 2004 In: Vitamin and mineral requirements in human nutrition: report of a joint $\mathrm{FAO} / \mathrm{WHO}$ expert consultation. Bangkok, Thailand, 21-30 September 1998, pp. 305-306. Accessed at http://www.who.int/ vmnis/en

8. Bürgi H, 2010 Iodine excess. Best Pract Res Clin Endocrinol Metab 24: 107-115.

9. Müssig K 2009 Iodine-induced toxic effects due to seaweed consumption. In Preedy VR, Burrow GN, \& Ross Watson R (eds) Comprehensive Handbook of Iodine Amsterdam: Elsevier pp, 897-908.

10. Roti E, Braverman LE 1996 Iodine excess and thyroid function. In Nauman J, Glinoer D, Braverman LE \& Hostalek U (eds), The Thyroid and Iodine Stuttgart: Schattauer pp, 7-17.

11. Zimmermann MB, Jooste PL, Pandav CS, 2008 Iodine deficiency disorders. Lancet 372:1251-1262.

12. Utiger RD, 2006 Iodine nutrition - more is better. $\mathrm{N}$ Engl J Med 354: 2819-2821.

13. Camargo R, Knobel M, Medeiros-Neto G, 2007 Iodine nutrition: more is better? Arq Bras Endocrinol Metab 51: 639-640.

14. Pearce EN, Pino S, He X, et al, 2004 Sources of dietary iodine: bread, cow's milk, and infant formula in the Boston area. J Clin Endocrinol Metab 89: 3421-3424.

15. Pedersen KM, Laurberg P, Nøhr S, et al, 1999 Iodine in drinking water varies by more than 100 -fold in Denmark: importance for iodine content in infant formulas. Eur J Endocrinol 140: 400-403. 
16. Rose NR, Witebsky E, 1956 Studies on organ specificity. V. Changes in the thyroid glands of rabbits following active immunization with rabbit thyroid extract. J Immunol 76: 417-427.

17. Ban Y, Greenberg DA, Concepcion E, Skrabanek L, Villanueva R, Tomer Y, 2003 Amino acid substitutions in the thyroglobulin gene are associated with susceptibility to human and murine autoimmune thyroid disease. Proc Natl Acad Sci U S A 100: 15119-15124.

18. Tomer Y, Greenberg DA, Concepcion E, Ban Y, Davies TF, 2002 Thyroglobulin is a thyroid specific gene for the familial autoimmune thyroid diseases. J Clin Endocrinol Metab 87: 404-407.

19. Tomer Y, Greenberg D, 2004 The thyroglobulin gene as the first thyroid-specific susceptibility gene for autoimmune thyroid disease. Trends Mol Med 10: 306-308.

20. Carayanniotis G, 2007 Recognition of thyroglobulin by T cells: the role of iodine. Thyroid 17: 963-973.

21. Gentile F, Conte M, Formisano S, 2004 Thyroglobulin as an autoantigen: what can we learn about immunopathogenicity from the correlation of antigenic properties with protein structure? Immunology 112: 13-25.

22. Champion BR, Page KR, Parish N, et al, 1991 Identification of a thyroxine-containing self-epitope of thyroglobulin which triggers thyroid autoreactive $\mathrm{T}$ cells 6. J Exp Med 174: 363-370.

23. Hutchings PR, Cooke A, Dawe K, et al, 1992 A thyroxinecontaining peptide can induce murine experimental autoimmune thyroiditis. J Exp Med 175: 869-872.

24. Braley-Mullen H, Sharp GC, 1997 A thyroxine-containing thyroglobulin peptide induces both lymphocytic and granulomatous forms of experimental autoimmune thyroiditis. J Autoimmun 10: 531-540.

25. Wan Q, McCormick DJ, David CS, Kong YC, 1998 Thyroglobulin peptides of specific primary hormonogenic sites can generate cytotoxic $\mathrm{T}$ cells and serve as target autoantigens in experimental autoimmune thyroiditis. Clin Immunol Immunopathol 86: 110-114.

26. Dunn JT, Anderson PC, Fox JW, et al, 1987 The sites of thyroid hormone formation in rabbit thyroglobulin. J Biol Chem 262: 16948-16952.

27. Marriq C, Lejeune PJ, Malthiery Y, Rolland M, Lissitzky S, 1984 Precursor-product relationship between the $26-\mathrm{kDa}$ and $18-\mathrm{kDa}$ fragments formed by iodination of human thyroglobulin. FEBS Lett 175: 140-146.

28. Kong YC, McCormick DJ, Wan Q, et al, 1995 Primary hormonogenic sites as conserved autoepitopes on thyroglobulin in murine autoimmune thyroiditis. Secondary role of iodination. J Immunol 155: 5847-5854.

29. Flynn JC, McCormick DJ, Brusic V, et al, 2004 Pathogenic human thyroglobulin peptides in HLA-DR3 transgenic mouse model of autoimmune thyroiditis. Cell Immunol 229: 79-85.

30. Muixi L, Alvarez I, Jaraquemada D, 2008 Peptides presented in vivo by HLA-DR in thyroid autoimmunity. Adv Immunol 99: 165-209.
31. Muixi L, Carrascal M, Alvarez I, et al, 2008 Thyroglobulin peptides associate in vivo to HLA-DR in autoimmune thyroid glands. J Immunol 181: 795-807.

32. Wan Q, Motte RW, McCormick DJ, et al, 1997 Primary hormonogenic sites as conserved autoepitopes on thyroglobulin in murine autoimmune thyroiditis: role of MHC class II. Clin Immunol Immunopathol 85: $187-$ 194.

33. Leonardi A, Acquaviva R, Marinaccio M, et al, 1994 Presence of dityrosine bridges in thyroglobulin and their relationship with iodination. Biochem Biophys Res Commun 202: 38-43

34. Li HS, Carayanniotis G, 2006 Iodination of tyrosyls in thyroglobulin generates neoantigenic determinants that cause thyroiditis. J Immunol 176: 4479-4483.

35. Li HS, Jiang HY, Carayanniotis G, 2007 Modifying effects of iodine on the immunogenicity of thyroglobulin peptides. J Autoimmun 28: 171-176.

36. Jiang HY, Li HS, Carayanniotis K, Carayanniotis G, 2007 Variable influences of iodine on the T-cell recognition of a single thyroglobulin epitope. Immunology 121: 370-376.

37. Saboori AM, Rose NR, Bresler HS, Vladut-Talor M, Burek CL, 1998 Iodination of human thyroglobulin (Tg) alters its immunoreactivity. I. Iodination alters multiple epitopes of human Tg. Clin Exp Immunol 113: 297-302.

38. Saboori AM, Rose NR, Burek CL, 1998 Iodination of human thyroglobulin $(\mathrm{Tg})$ alters its immunoreactivity. II. Fine specificity of a monoclonal antibody that recognizes iodinated Tg. Clin Exp Immunol 113: 303-308.

39. Edelhoch H, Carlomagno MS, Salvatore G, 1969 Iodine and the structure of thyroglobulin. Arch Biochem Biophys 134: 264-260.

40. Fouchier F, Mego JL, Dang J, Simon C, 1983 Intralysosomal hydrolysis of thyroglobulin. II. Different fates of poorly and fully iodinated $\mathrm{Tg}$ and specific activation by TSH of the degradation of fully iodinated Tg. Acta Endocrinol (Copenh) 103: 62-67.

41. Lamas L, Ingbar SH, 1978 The effect of varying iodine content on the susceptibility of thyroglobulin to hydrolysis by thyroid acid protease. Endocrinology 102: 188-197.

42. Dai YD, Rao VP, Carayanniotis G, 2002 Enhanced iodination of thyroglobulin facilitates processing and presentation of a cryptic pathogenic peptide. J Immunol 168: 5907-5911.

43. Duthoit C, Estienne V, Delom F, et al, 2000 Production of immunoreactive thyroglobulin C-terminal fragments during thyroid hormone synthesis. Endocrinology 141: 2518-2525.

44. Lehmann PV, Sercarz EE, Forsthuber T, Dayan CM, Gammon G, 1993 Determinant spreading and the dynamics of the autoimmune T-cell repertoire. Immunol Today 14: 203-208.

45. Gentile F, Salvatore G, 1993 Preferential sites of proteolytic cleavage of bovine, human and rat thyroglobulin. 
Eur J Ciochem 218: 603-621

46. Benvenga S, Trimarchi F, Robbins J, 1987 Circulating thyroid hormone autoantibodies. J Endocrinol Invest 10: 605-619.

47. Sakata S, 1994 Autoimmunity against thyroid hormones. Crit Rev Immunol 14: 157-191.

48. Dai YD, Eliades P, Carayanniotis KA, et al, 2005 Thyroxine-binding antibodies inhibit $\mathrm{T}$ cell recognition of a pathogenic thyroglobulin epitope. J Immunol 174: 3105-3110.

49. Dai Y, Carayanniotis KA, Eliades P, et al, 1999 Enhancing or suppressive effects of antibodies on processing of a pathogenic $\mathrm{T}$ cell epitope in thyroglobulin. J Immunol 162: 6987-6992.

50. Barin JG, Talor MV, Sharma RB, Rose NR, Burek CL, 2005 Iodination of murine thyroglobulin enhances autoimmune reactivity in the NOD.H2 mouse. Clin Exp Immunol 142: 251-259.

51. Champion BR, Rayner DC, Byfield PG, Page KR, Chan CT, Roitt IM, 1987 Critical role of iodination for T cell recognition of thyroglobulin in experimental murine thyroid autoimmunity. J Immunol 139: 3665-3670.

52. Ebner SA, Lueprasitsakul W, Alex S, Fang SL, Appel MC, Braverman LE, 1992 Iodine content of rat thyroglobulin affects its antigenicity in inducing lymphocytic thyroiditis in the BB/Wor rat. Autoimmunity 13: 209-214.

53. Rose NR, Rasooly L, Saboori AM, Burek CL, 1999 Linking iodine with autoimmune thyroiditis. Environ Health Perspect 107: Suppl 5: 749-752.

54. Sundick RS, Herdegen DM, Brown TR, Bagchi N, 1987 The incorporation of dietary iodine into thyroglobulin increases its immunogenicity. Endocrinology 120: 2078-2084.

55. Allen EM, Thupari JN, 1995 Thyroglobulin-reactive $\mathrm{T}$ lymphocytes in thyroiditis-prone $\mathrm{BB} /$ Wor rats. $\mathrm{J}$ Endocrinol Invest 18: 45-49.

56. Li HS, Carayanniotis G, 2007 Induction of goitrous hypothyroidism by dietary iodide in SJL Mice. Endocrinology 148: 2747-2752.

57. Kolypetri P, Noel NA, Carayanniotis KA, Carayanniotis G, 2010 Iodine content of thyroglobulin in NOD.H$2 \mathrm{~h} 4$ mice developing iodine-accelerated autoimmune thyroiditis. Hormones (Athens) 9: 151-160.

58. Rasooly L, Rose NR, Saboori AM, Ladenson PW, Burek CL, 1998 Iodine is essential for human T cell recognition of human thyroglobulin. Autoimmunity 27: 213-219.

59. Shimojo N, Saito K, Kohno Y, Sasaki N, Tarutani O, Nakajima H, 1988 Antigenic determinants on thyroglobulin: comparison of the reactivities of different thyroglobulin preparations with serum antibodies and $\mathrm{T}$ cells of patients with chronic thyroiditis. J Clin Endocrinol Metab 66: 689-695.

60. Bagchi N, Brown TR, Sundick RS, 1995 Thyroid cell injury is an initial event in the induction of autoimmune thyroiditis by iodine in obese strain chickens.
Endocrinology 136: 5054-5060.

61. Belshaw BE, Becker DV, 1973 Necrosis of follicular cells and discharge of thyroidal iodine induced by administering iodide to iodine-deficient dogs. J Clin Endocrinol Metab 36: 466-474.

62. Follis RH, Jr, 1959 Thyroiditis resulting from administration of excess iodine to hamsters with hyperplastic goiters. Proc Soc Exp Biol Med 102: 425-429.

63. Li M, Eastman CJ, Boyages SC, 1993 Iodine induced lymphocytic thyroiditis in the $\mathrm{BB} / \mathrm{W}$ rat: early and late immune phenomena. Autoimmunity 14: 181-187.

64. Mahmoud I, Colin I, Many MC, Denef JF, 1986 Direct toxic effect of iodide in excess on iodine-deficient thyroid glands: epithelial necrosis and inflammation associated with lipofuscin accumulation. Exp Mol Pathol 44: 259271.

65. Many MC, Denef JF, Hamudi S, Cornette C, Haumont S, Beckers C, 1986 Effects of iodide and thyroxine on iodine-deficient mouse thyroid: a morphological and functional study. J Endocrinol 110: 203-210.

66. Many MC, Mestdagh C, van den Hove MF, Denef JF, 1992 In vitro study of acute toxic effects of high iodide doses in human thyroid follicles. Endocrinology 131: 621-630.

67. Many MC, Maniratunga S, Varis I, Dardenne M, Drexhage HA, Denef JF, 1995 Two-step development of Hashimoto-like thyroiditis in genetically autoimmune prone non-obese diabetic mice: effects of iodine-induced cell necrosis. J Endocrinol 147: 311-320.

68. Kahaly GJ, Dienes HP, Beyer J, Hommel G, 1998 Iodide induces thyroid autoimmunity in patients with endemic goitre: a randomised, double-blind, placebo-controlled trial. Eur J Endocrinol 139: 290-297.

69. Mizukami Y, Michigishi T, Nonomura A, et al, 1993 Iodine-induced hypothyroidism: a clinical and histological study of 28 patients. J Clin Endocrinol Metab 76: 466-471.

70. Tajiri J, Higashi K, Morita M, Umeda T, Sato T, 1986 Studies of hypothyroidism in patients with high iodine intake. J Clin Endocrinol Metab 63: 412-417.

71. Weaver DK, Batsakis JG, Nishiyama RH, 1969 Relationship of iodine to "lymphocytic goiters". Arch Surg 98: 183-186.

72. Bonita RE, Rose NR, Rasooly L, Caturegli P, Burek CL, 2002 Adhesion molecules as susceptibility factors in spontaneous autoimmune thyroiditis in the NOD-H2h4 mouse. Exp Mol Pathol 73: 155-163.

73. Sharma RB, Alegria JD, Talor MV, Rose NR, Caturegli P, Burek CL, 2005 Iodine and IFN-gamma synergistically enhance intercellular adhesion molecule 1 expression on NOD.H-2h4 mouse thyrocytes. J Immunol 174: 7740-7745.

74. Burek CL, Rose NR, 2008 Autoimmune thyroiditis and ROS. Autoimmun Rev 7: 530-537.

75. Sharma R, Traore K, Trush MA, Rose NR, Burek CL, 2008 Intracellular adhesion molecule-1 up-regulation 
on thyrocytes by iodine of non-obese diabetic. H2(h4) mice is reactive oxygen species-dependent. Clin Exp Immunol 152: 13-20.

76. Bagchi N, Brown TR, Herdegen DM, Dhar A, Sundick RS, 1990 Antioxidants delay the onset of thyroiditis in obese strain chickens. Endocrinology 127: 1590-1595.

77. Beckett GJ, Arthur JR, 2005 Selenium and endocrine systems. J Endocrinol 184: 455-465

78. Duthoit C, Estienne V, Giraud A, et al, 2001 Hydrogen peroxide-induced production of a $40 \mathrm{kDa}$ immunoreactive thyroglobulin fragment in human thyroid cells: the onset of thyroid autoimmunity? Biochem J 360: 557-562.

79. Teng X, Shan Z, Teng W, Fan C, Wang H, Guo R, 2009 Experimental study on the effects of chronic iodine excess on thyroid function, structure, and autoimmunity in autoimmune-prone NOD.H-2h4 mice. Clin Exp Med 9: 51-59. 